\title{
Synthetic cannabinoids
}

\author{
Rabia Bilici \\ Erenkoy Mental Health and Neurology Training and Research Hospital, Istanbul, Turkey
}

\begin{abstract}
Use of cannabinoids is increasing at an alarming rate. Their easy availability, cheapness, perceptive legality and difficulty in detecting its presence with standard urine toxicologic tests, and similar factors probably contribute to the increased use, and popularity of synthetic cannabinoids. Although laws, and regulations concerning auditing of these substances have been implemented in many countries, production of new types of synthetic cannabinoids rapidly takes place. Primary psychoactive ingredient of cannabis is $\Delta$ 9-tetrahydrocannabinoid which is partial agonist of cannabinoid receptors, while synthetic cannabinoids are potent, and complete agonists of these receptors. Therefore it is not surprising that synthetic cannabinoids exert more powerful effects than cannabinoids. Clinical effects of synthetic cannabinoids can cause referrals to emergency services, and hospitalizations. Despite lack of any specific therapy benzodiazepines, antipsychotics, and fluid replacement may be required. Clinical follow-up studies are needed for better comprehension of its clinical effects, and treatment outcomes.
\end{abstract}

Key words: Cannabis; CB1; synthetic cannabinoid.

$\mathrm{I}^{\mathrm{n}}$ nvestigators, and clinicians have not adequate information about synthetic cannabinoids (SCs) which are becoming increasingly prevalent. In this article, we aimed to deal with available information about SCs in the light of the literature findings.

Cannabinoids basically divide into 3 groups as natural, endogenous, and synthetic cannabinoids. THC ( $\Delta 9$-tetrahydrocannabinoid) contained in the cannabis is the mostly known natural cannabinoid. From ancient times, their therapeutic effects have been utilized. However, its addictive potential was discerned at the beginning of the 20. century which led to restriction of their use [1]. Synthetic cannabinoids constitute a group of compounds which were produced in the laboratory during 1990s, with the intention to investigate endogenous cannabinoids, and create new treatment alternatives for medical use $[1,2]$. These heterogenous compounds are dissolved in a solvent, and sprayed on the plants. Solvent vaporizes, the plant is dried, pressed, and packaged [3]. Thus SCs are packaged as loose leaves or previously wrapped product, and rarely sold in powder form [4]. They are smoked like a hookah using a water pipe or wrapped in a cigarette paper before smoking. Various aromas are presumably added into some SC products so as to make its purchase more reasonable [2].

Substances containing synthetic cannabinoids

Received: November 22, 2014 Accepted: November 25, 2014 Online: December 08, 2014

Correspondence: Dr. Rabia BILICI. Erenkoy Ruh ve Sinir Hastaliklari Egitim ve Arastirma Hastanesi, Amatem Klinigi, Sinan Ercan Cad., No: 29, Erenköy, Kadikoy 34736, Istanbul, Turkey.

Tel: +90 216 - 3025959 e-mail: rabiabilici@hotmail.com

(c) Copyright 2014 by Istanbul Northern Anatolian Association of Public Hospitals - Available online at www.kuzeyklinikleri.com 
are generally called "Spice" in Europe, "K2" in USA, "Bonzai" or "Jamaika" in Turkey [1]. The name "spice" might be a reference to the spacecraft 'Spice' used for intergalactic journey mentioned in Frank Herbert's novel Dune [2].

In Europe, at the start of 2000s, SCs were synthetized in the laboratories, and marketed as legal cannabis alternatives in bright gelatin packages, and under various trade names. They soon became popular as "legal intoxicating agents" or "herbal intoxicating agents". They are sold as fine parfumes, incense, plant refreshing agents, and bath salt in some special "smart shops" or "head shops.", gas stations, and on-line with labels indicating that they are not for human use, but can be used for investigatonal purposes [5]. On the package labels only herbal ingredients of the product are listed without any mention of its synthetic cannabinoid content $[1,2]$.

John W. Huffman (JWH) listed the most detailed series of SC with cannabis-like effects on animals, and these indicated substances have become the main active agent of newly produced synthetic cannabinoids [6, 7]. Other SCs developed within the last 20 years belonged to AM (Alexandros Makriyannis) series, and they are indazolecarboxamide derivatives [7]. Up to now hundreds of synthetic cannabinoids have been categorized in various structural groups. These groups include adamantoil indoles, aminoalkyl indoles, benzoyl indoles, cyclohexylphenoles, dibenzopyrans, naphthyl methyl indoles, naphthyl methyl indenes, naphthoyl pyrroles, phenylacetylwne indoles, and indazole caboxamide products [7].

Many SCs are still categorized as pharmacologic agents, and subjected to USA Controlled Substances Act. As synthetic cannabinoids are included in the group of illicit substances, structurally different cannabimimetic compounds are produced which are not covered by laws, and regulations [7].

The first Spice products widely contained JWH018, and JWH-073, while with time new products have been added to the list. In the EMCDDA 2012 report 30 of 73 new psychoactive agents were indicated to be SC [8].

As reports indicate, most of the SC users also abuse other illicit substances, most frequently cannabis $[9,10]$. Other most commonly used substances include alcoholic drinks, cigarette, hallusinogens, prescribed opiates, benzodiazepines, amphetamines, and cocaine [2].

\section{Prevalence}

The prevalence of synthetic cannabinoids is not known completely. However despite all efforts against their use, as admitted worldwide, SCs have been used increasingly with their psychiatric, medical, and social outcomes [2].

In a recent review by Castaneto et al. nine SC epidemiological studies have been analyzed. The first of the two internationally organized self-reported studies was conducted on-line, and 13 countries, and 42 US states participated in the study. Most of the participants were single (67\%), male (83\%), and at least high school graduates (96\%). They began to use illicit substances at an average age of 27 years. Almost all of them were using alcoholic beverages (92\%), and marihuana (84\%). Most frequently SCs are smoked like a cigarette (water pipe/bong, cigarette, pipe, vs). However they are used via oral or rectal route or their vapours are inhaled. Curiosity is the first reason for starting to use these substances. The rates of abuse, addiction, and emergence of withdrawal symptoms related to SC use have been reported as 37,15 , and $15 \%$, respectively [7].

In the second globally conducted anonymous survey study, data of 14.966 participants were collected. The study participants consisted mostly $(2 / 3)$ of male individuals with a mean age of 26 years, and $2513(17 \%)$ of them reported that they had been using SC [10]. Most $(n=980 ; 98 \%)$ of the study participants who used SCs within the previous year had prevalently utilized cannabis, and other drugs. Despite rapid onset of activity of SCs relative to cannabis, later on $92.8 \%(n=887)$ of the study participants preferred to use cannabis because of unwanted effects of SCs. However $7.2 \%$ of the participants indicated that they had opted to use SC rather than cannabis. As rationale of their preference for SCs they set forward arguments as their easy availability, lower cost, effects, and inability to detect SCs with laboratory analyses [7].

As observed in many field studies, SCs are mostly used by adolescents, and adults, and more frequently attract the attention of cannabis, and multiple illicit substance users. Men prefer to use SCs 2-fold more frequently than women. US high school students 
perceive SCs as safer than other drugs. Military personnel, and athletes have also used SC to refrain from being caught doping $[2,7,9,11]$.

Cannabis users have begun to use SCs while they were undergoing regular laboratory tests for the detection of illicit substance during supervised release period [2]

\section{Pharmacology}

It has been detected that synthetic cannabinoids exert their effects by binding to $\mathrm{CBI}$, and $\mathrm{CB} 2$ receptors just like THC which is the primary psychoactive substance of cannabis [12]. CB1 receptors are found in central, and peripheral nervous system, bone, heart, liver, lungs, vascular endothelium, and reproductive system [13]. However they are primarily located in the brain, and they are responsible for psychoactive effects of cannabinoids. CB2 receptors are primarily found in the immune system, and also in the central nervous system. CB2 receptors are detected in smaller numbers relative to $\mathrm{CB} 1$ receptors, and mediate immunoregulatory effects of cannabinoids [7].

Contrary to THC, SCs are potent, and complete agonists of cerebral CB1 receptors [10] Synthetic cannabinoids activate CB1 receptors. G-protein mediated receptors primarily located at presynaptic terminals. Activation of CB1 receptors decrease cyclic adenosin monophosphate (cAMP) activity, and disclose cannabimimetic responses [14]. SC agonists interact with voltage-gated ion channels, decrease membrane potential, and consequently inhibit potassium, sodium, and $\mathrm{N}$-, and $\mathrm{P} / \mathrm{Q}$ type calcium channels [7].

THC which is the primary psychoactive substance of cannabis is a partial agonist of cannabinoid receptors, while SCs are potent, and complete agonists of these receptors. More intensive effects produced with SCs when compared with cannabis should not be surprising [15].

Contrary to synthetic cannabinoids, cannabis contains approximately 70 flavonoids, and other cannabinoids which can alter the effects of THC. For example, cannabidiol (CBD) which is a type of cannabinoid with established anxiolytic, and antipsychotic effects can balance some anxiogenic, and psychomimetic effects of THC $[2,16]$.
Packages of synthetic cannabinoids contain synthetic cannabinoids from different chemical categories, and their composition is continually modified. Composition, and amount of the same product produced at different time periods, even products in the same package differ considerably. In addition to synthetic cannabinoids, as indicated in various studies, these packages also contain additives, preservatives, fatty acids, esthers, benzodiazepines, and active metabolite of tramadol $[7,17,18]$.

Some difficulties encountered in the detection of synthetic cannabinoids in urine, sputum, and serum samples of synthetic cannabinoid users. Some synthetic cannabinoids including JWH-018, and their metabolites in the serum can be measured using liquid chromatography tandem mass spectrometry (LC-MS/MS), and gas chromatography mass spectrometry (GC/MS). However LC-MS/MS and GC/MS methods are time consuming, and it is difficult to use these methods in a field study [2].

\section{Their clinical efects}

Randomized controlled studies have not been conducted with synthetic cannabinoids so far. Very scarce number of cannabinoids have been tested in human beings [19]. Most of the information on this subject comes from on-line interactive live forums, emergency service calls, Poison Control Centers, and case reports in the medical literature. Medical literature mostly retrieve information from case reports related to addicts consulted to emergency services [2].

Most of the acute phase effects of synthetic cannabinoids resemble those of the cannabis, while significant differences exist in the variety, and severity of these effects. It is not known whether these differences stem from the differences between SCs, and cannabis or originate from non-cannabinoid components contained in the composition of SC [2]. Interactions between more than one SC components contained in a single product may effect clinical manifestations.

Clinical symptoms may onset immediately within minutes or hours after use of SC, however, duration of symptoms are variable, and they may persist for hours. Some users may experience residual effects lasting for hours. Cases of agitated delirium lasting for hours have been reported [2, 19, 20,21]. 
Calls made at The American Association Poison Control Centers, and referrals to emergency services have increased rapidly from the year 2010 on [21,22]. Number of referrals to emergency services increased tremendously $(\mathrm{n}=11406$ in 2010, and 28.531 in 2014) [7]. In 2010, 464 SC users (males, $739 \%$, and females 25\%; age range $12-67$ years) consulted to Texas Poison Control Centers [7, 23]. Adverse clinical effects were grouped as neurological (61.9\%), cardiovascular (43.9\%), gastrointestinal $(21.1 \%)$, respiratory $(8.0 \%)$, ocular $(5.0 \%)$, cutaneous $(2.6 \%)$, renal $(0.9 \%)$, hematologic $(0.4 \%)$, and other side (acidosis, hyperglycemia, diaphoresis etc.) (25.9\%) effects. Any case of fatality was not reported in association with synthetic cannaboid use, while $59.9 \%$ of the patients demonstrated "moderate or major" toxicity symptoms. Treatment modalities consisted of i.v. fluids (38.8\%), benzodiazepines (18.5\%), oxygen therapy (8.0\%), and antiemetics [23].

Intoxication: In 51 articles on synthetic cannabinoid intoxication more than 200 cases have been reported. The age distribution of these cases has ranged between 13 , and 59 years (mean, 22; median 20 yrs) [7].

Symptoms of the acute phase (within the frst 24 hours): Symptoms of this phase include agitation or irritability, restlessness, anxiety, confusion, short-lived impairment of memory, and cognition, changes in perception, and psychosis. Physical findings include dilated pupils, conjunctival hyperemia, nausea and vomiting, impaired speech, shortness of breath, hypertension, tachycardia, chest pain, muscle twitchings, and sweating or pale skin. Physical examination, clinical, and laboratory tests, and electrocardiographic (ECG) examination results are within normal limits, however in some patients with leucocytosis (WBC counts $13.000-14.000 / \mathrm{mm}^{3}$ ) or hypokalemia $(<3.5 \mathrm{mEq} / \mathrm{L})$ some abnormalities could be seen. Hyperglycemia was observed. Some patients reported that the effect of SCs started within minutes after intake of the SC, and signs of intoxication became manifest 2-5 hours after its use. They also indicated that the symptoms of intoxication resolved within less than 24 hours [7]. After synthetic cannabinoid use panic attacks, suicidal thoughts, and attempts have been also reported [2].

Subacute phase: (24 hours after their intake): Serious medical complications developed during this phase include myocardial infarction, ischemic stroke, seizures, and acute renal injury. In some patients who developed acute renal injury required hemodialysis, and corticosteroid therapy, while health state of others improved within 3 days after admission to hospital [7].

Withdrawal symptoms: In two case reports cited in the medical literature, diaphoresis (sweating), uneasy feelings, tremor, somatic pain, palpitations, insomnia, tachycardia, hypertension, hyperventilation, headache, diarrhea, nausea, vomiting, and depressive mood have been documented. Even some withdrawal symptoms which lasted for longer periods have resolved within a week $[2,5]$.

Psychotic Reactions: Among psychotic symptoms associated with synthetic cannabinoids, changes in perception, illusions, auditory, and visual hallucinations, paranoia, agitation, aggression, depersonalization, catatonia, and dissociation can be enumerated. The users have indicated fascinating visual effects, and defined them as "impressions", "bursts of colour", and "geometric patterns". Hallucinations are typically different from those reported for endogenous psychoses. Psychotic symptoms typically do not last more than a few hours, in some case reports, patients with prolonged psychotic symptoms have been presented [2].

Some publications have advocated that synthetic cannabinoids trigger psychosis in apparently healthy individuals aged 20-30 years without any previously experienced psychiatric disease. Following use of synthetic cannabinoids new cases of psychosis associated with paranoias, thought disorders, and suicidal thoughts have been detected. These individuals required hospitalization in psychiatry clinics for antipsychotic therapy. Psychotic periods vary between 1 week and 5 months [7]. Exposure to cannabis, and cannabinoid agonists, and development of psychosis are related to activation of CBI receptors $[2,24]$.

THC which is the main active ingredient of cannabis has been suspected to be the principal agent responsible for the development of psychosis. However cannabidiol (CBD) which is among its other ingredients can weaken psychotic effects of THC. However synthetic cannabinoids do not contain cannabinoids like CBD [2].

In adolescents, exposure to cannabis is thought 
to contribute to the increased risk of psychosis during advanced stages of life $[2,24]$. In addition, a linear dose-response relationship is apparent. Longer exposures increase the risk of psychosis. In consideration of higher potency of synthetic cannabinoids relative to $\mathrm{THC}$, increasing rates of $\mathrm{SC}$ use which lead to newly diagnosed cases of psychosis is also an alarming issue. It is acknowledged that in individuals with psychotic disorders SCs can precipitate psychosis [2].

Neurological side efects: Among side effects reported for synthetic cannabinoids, tremor, ataxia, nystagmus, fasciculations, hypertonicity, hyperreflexion, and hyperextension can be enumerated. The most common cognitive effect of synthetic cannabinoids is impairment of attention, concentration, memory, and operational skills. These effects are generally seen during intoxication period, however they can extend beyond this period [2, 25]. Epileptic seizures can be observed due to synthetic cannabinoid use [26].

Cardiovascular side effects: Most prevalent side effects of SCs include tachycardia, and hypertension. Patients can present with palpitations, chest pain or arrhytmia. In rare cases, synthetic cannabinoids have been suspected to induce myocardial infarction or even death. However coronary artery spasms can be presumably associated with other ingredients of SC $[2,26,27]$.

Gastrointestinal side efects: Synthetic cannabinoids can induce vomiting, and nausea, and increase appetite. However their users have indicated that SCs increased appetite less frequently than cannabis $[2,10]$.

Other side effects: Synthetic cannabinoids can at the same time cause pupillary changes as mouth dryness, conjunctival hyperemia, miosis, and midriasis, blurred vision, sensitivity to light, coughing, and pulmonary inflammation. Other symptoms as hyperthermia, rhabdomyolysis, tinnitus, and symptoms suggesting their anticholinergic effects have been also reported [2].

Mortality: Only four cases of mortality have been reported which were directly associated with synthetic cannabinoid use [7].

Their effects on laboratory parameters: Hyperglycemia, hypokalemia, increased creatinine, creatinine phosphokinase levels, acidosis, and leu- kocytosis have been reported related to synthetic cannabinoid use [2].

\section{Treatment}

A specific antidote for synthetic cannabinoid does not exist. Limited data suggest that benzodiazepines or antipsychotics can be effective as supportive, and symptomatic treatment. Among benzodiazepines, more frequently lorazepam, and as antipsychotics more often haloperidol, olanzapine, and quetiapine have been used. Theoretically, CBI receptor antagonists can reverse CBI agonistic effects of SCs, however commercially marketed CBI receptor antagonists are not available [2]. Vital signs of the patients should be monitored, fluid replacement should be made to prevent dehydration, and rhabdomyolysis. Diphenhydramine can be used to relieve muscular rigidity $[2,28,29,30]$.

\section{DISCUSSION}

Despite many measures, and legal prohibitions, use of synthetic cannabinoids are increasing at an alarming speed. Although many regulations, and laws are implemented to audit the use of these illicit substances, novel synthetic cannabinoids are produced in no time at all $[2,7]$. Problems related to these substances with increasing prevalence seem to continue to engage health care professionals during their daily practice. Therefore health care professionals should be knowledgeable about diagnosis, and treatment of clinical entities related to SC use, and they should be able to differentiate among various clinical manifestations of SCs. Besides forensic medicine specialists should not forget that during evaluation process standard toxicology tests may not detect SC.

Since limited number of epidemiological data are available on synthetic cannabinoid use, their pharmacokinetics, and distribution patterns in tissues/organs, elimination, drug-drug interactions, and clinical effects, larger-scale investigation should be performed on these issues.

Conflict of Interest: No conflict of interest was declared by the authors.

Financial Disclosure: The authors declared that this study has received no financial support. 


\section{REFERENCES}

1. Evren C, Bozkurt M. Düşünen Adam. The Journal of Psychiatry and Neurological Sciences 2013;26:1-11.

2. Spaderna M, Addy PH, D'Souza DC. Spicing things up: synthetic cannabinoids. Psychopharmacology (Berl) 2013;228:525-40.

3. Musah RA, Domin MA, Walling MA, Shepard JR. Rapid identification of synthetic cannabinoids in herbal samples via direct analysis in real time mass spectrometry. Rapid Commun Mass Spectrom 2012;26:1109-14. CrossRef

4 Kikura-Hanajiri R, Uchiyama N, Goda Y. Survey of current trends in the abuse of psychotropic substances and plants in Japan. Leg Med (Tokyo) 2011;13:109-15. CrossRef

5. Vandrey R, Dunn KE, Fry JA, Girling ER. A survey study to characterize use of Spice products (synthetic cannabinoids). Drug Alcohol Depend 2012;120:238-41. CrossRef

6. Huffman JW, Dai D. Design, synthesis and pharmacology of cannabimimetic indoles. Bioorganic Medicinal Chemistery Letters 1994;4:563-6. CrossRef

7. Castaneto MS, Gorelick DA, Desrosiers NA, Hartman RL, Pirard S, Huestis MA. Synthetic cannabinoids: Epidemiology, pharmacodynamics, and clinical implications. Drug Alcohol Depend 2014;144:12-41. CrossRef

8. Annual report on the state of the drugs problem in Europe, EMCDDA, Lisbon, 2012.

9. Barratt MJ, Cakic V, Lenton S. Patterns of synthetic cannabinoid use in Australia. Drug Alcohol Rev. 2013;32:141-6. CrossRef

10. Winstock AR, Barratt MJ. Synthetic cannabis: a comparison of patterns of use and effect profile with natural cannabis in a large global sample. Drug Alcohol Depend 2013;131:106-11. CrossRef

11. Hu X, Primack BA, Barnett TE, Cook RL. College students and use of K2: an emerging drug of abuse in young persons. Subst Abuse Treat Prev Policy 2011;6:16. CrossRef

12. Wiley JL, Marusich JA, Huffman JW. Moving around the molecule: relationship between chemical structure and in vivo activity of synthetic cannabinoids. Life Sci 2014;97:55-63. CrossRef

13. Howlett AC, Barth F, Bonner TI, Cabral G, Casellas P, Devane WA, et al. International Union of Pharmacology. XXVII. Classification of cannabinoid receptors. Pharmacol Rev 2002;54:161-202. CrossRef

14. Pertwee RG. Receptors and channels targeted by synthetic cannabinoid receptor agonists and antagonists. Curr Med Chem 2010;17:1360-81. CrossRef

15. Atwood BK, Huffman J, Straiker A, Mackie K. JWH018, a common constituent of 'Spice' herbal blends, is a potent and efficacious cannabinoid CB receptor agonist. Br J Pharmacol 2010;160:585-93. CrossRef

16. Leweke FM, Piomelli D, Pahlisch F, Muhl D, Gerth CW, Hoyer $\mathrm{C}$, et al. Cannabidiol enhances anandamide signaling and alle- viates psychotic symptoms of schizophrenia. Transl Psychiatry 2012;2:e94. CrossRef

17. Zuba D, Byrska B, Maciow M. Comparison of "herbal highs" composition. Anal Bioanal Chem 2011;400:119-26. CrossRef

18 Dresen S, Ferreirós N, Pütz M, Westphal F, Zimmermann R, Auwärter V. Monitoring of herbal mixtures potentially containing synthetic cannabinoids as psychoactive compounds. J Mass Spectrom 2010;45:1186-94. CrossRef

19. Auwärter V, Dresen S, Weinmann W, Müller M, Pütz M, Ferreirós N.'Spice' and other herbal blends: harmless incense or cannabinoid designer drugs? J Mass Spectrom 2009;44:832-7. CrossRef

20. Berry-Cabán CS, Ee J, Ingram V, Berry CE, Kim EH. Synthetic cannabinoid overdose in a 20-year-old male US soldier. Subst Abus 2013;34:70-2. CrossRef

21. Heath TS, Burroughs Z, Thompson AJ, Tecklenburg FW. Acute intoxication caused by a synthetic cannabinoid in two adolescents. J Pediatr Pharmacol Ther 2012;17:177-81.

22. Bronstein AC, Spyker DA, Cantilena LR Jr, Rumack BH, Dart RC. 2011 Annual report of the American Association of Poison Control Centers' National Poison Data System (NPDS): 29th Annual Report. Clin Toxicol (Phila) 2012;50:911-1164. CrossRef

23. Forrester MB, Kleinschmidt K, Schwarz E, Young A. Synthetic cannabinoid and marijuana exposures reported to poison centers. Hum Exp Toxicol 2012;31:1006-11. CrossRef

24. Sewell RA, Skosnik PD, Garcia-Sosa I, Ranganathan M, D'Souza DC. Behavioral, cognitive and psychophysiological effects of cannabinoids: relevance to psychosis and schizophrenia. [Article in Portuguese] Rev Bras Psiquiatr 2010;32 Suppl 1:S15-30. [Abstract]

25. Musshoff F, Madea B, Kernbach-Wighton G, Bicker W, Kneisel $\mathrm{S}$, Hutter M, et al. Driving under the influence of synthetic cannabinoids ("Spice"): a case series. Int J Legal Med 2014;128:5964. CrossRef

26. Hoyte CO, Jacob J, Monte AA, Al-Jumaan M, Bronstein AC, Heard KJ. A characterization of synthetic cannabinoid exposures reported to the National Poison Data System in 2010. Ann Emerg Med 2012;60:435-8. CrossRef

27. Mir A, Obafemi A, Young A, Kane C. Myocardial infarction associated with use of the synthetic cannabinoid K2. Pediatrics 2011;128:e1622-7.

28. Lindsay L, White ML. Herbal marijuana alternatives and bath salts 'barely legal' toxic highs. Clinical Pediatric Emergency Medicine 2012;13:283-91. CrossRef

29. Nacca N, Vatti D, Sullivan R, Sud P, Su M, Marraffa J. The synthetic cannabinoid withdrawal syndrome. J Addict Med 2013;7:296-8. CrossRef

30. Cohen J, Morrison S, Greenberg J, Saidinejad M. Clinical presentation of intoxication due to synthetic cannabinoids. Pediatrics 2012;129:e1064-7. CrossRef 